\title{
STRATEGIES TO INCREASE ONLINE STUDENT SUCCESS FOR STUDENTS WITH DISABILITIES
}

\author{
Kristen Betts, EdD
}

Forbes Education

Alex H. Cohen, MS

Drexel University

Daniel P. Veit, $M S$

Texas School for the Deaf

Henry C. Alphin Jr., MS

Drexel University and Warwick Business School

Chanel Broadus, $M S$

Camden County College

Dan Allen

Drexel University

\begin{abstract}
Online learning provides extensive opportunities for individuals with disabilities to enroll in degree and certificate programs. However, accessibility must be central to online course development since this can have a profound effect on student engagement, academic performance, and completion rates. This article provides a unique perspective on accessibility in online learning. One current online student and three alumni of online programs provide video self-introductions, an overview of their online experience, and strategies for increasing student success in online courses and programs for students with disabilities. Strategies are also shared for integrating accessibility as a critical component into faculty development to ensure accessibility goes beyond the office of disability services and becomes an integral part of online teaching, learning, and assessment.
\end{abstract}

\section{KEYWORDS}

Online learning, distance education, access, accessibility, disability, engagement, retention, attrition, student success, program development, faculty development, personas

\section{INTRODUCTION}

The ubiquity of technology and telecommunications has transformed higher education by extending the traditional brick-and-mortar classroom literally to the "clouds." Thanks to the Internet and learning management systems, students today can enroll in online courses and online degree and certificate programs anywhere in the world through personal computers, laptops, and mobile devices. However, for students with disabilities, increased access to higher education does not necessarily equate to increased accessibility in terms of course content, learning activities, and assessment. As institutions continue to expand online courses and programs, accessibility should be central to course development and faculty 
development since this can have a profound effect on student engagement, academic performance, and completion rates.

Research reveals approximately 20 percent of the general population self-identify as having a disability [1]. However, colleges/universities often point out that student reporting rates are lower than national reporting rates with only 11 percent of postsecondary students self-identifying as having a disability [2]. This means that many students with disabilities may not be getting the services they need to succeed in their programs - particularly in online programs in which students may infrequently or never come to campus. Therefore, accessibility and support services must be at the forefront when universities are developing online programs, online course content, cocurricular programming, and faculty development.

This article provides a unique perspective on accessibility in online learning. One current online student and three recent graduates of online programs discuss their personal experience with online learning and share strategies for increasing student success in online courses and programs for students with disabilities. Strategies are also shared for integrating accessibility as a critical area within faculty development to ensure accessibility goes beyond the office of disability services and becomes an integral part of online teaching, learning, and assessment.

\section{REVIEW OF LITERATURE}

\section{A. Growth of Online Learning and Online Attrition}

The growth of online learning has been explosive. According to the report Changing Course: Ten Years of Tracking Online Education in the United States, the number of students enrolling in at least one online course increased over 570,000 students between fall 2011 and fall 2012 to a new total of 6.7 million [3]. This represents the same approximate growth of additional students taking at least one online course as the previous year. The report also shares that the "proportion of all students taking at least one online course is at an all-time high of 32.0 percent" [3, p. 4].

Online enrollments in the United States are not expected to slow down. Ambient Insight forecasts the following:

By 2015, 25 million post-secondary students in the United States will be taking classes online. And as that happens, the number of students who take classes exclusively on physical campuses will plummet, from 14.4 million in 2010 to just 4.1 million five years later [4].

Attrition in online learning in the United States is often cited as occurring at a rate of 20-50 percent [5, 6]. However, some publications cite online attrition rates as high as 70-80 percent [7,8]. According to Angelino, Williams, and Natvig, online attrition is 10-20 percent higher than in traditional on-campus programs [9]. The challenge with online attrition is that there is comparatively limited data on national attrition rates. Eduventures summarizes the situation as follows:

Program-level online student retention and completion data in the public domain is almost non-existent. Delivery mode is not a variable used by the National Center for Education Statistics, the main source of retention and completion data for U.S. higher education. The literature on online student retention and completion data for U.S. higher education is dominated by course-level analysis [10, p. 4].

\section{B. Online Learning and Individuals with Disabilities}

Currently, there is no available national data on the percentage of students with disabilities who are enrolled in online programs. Two challenges exist in terms of collecting this type of data: (1) variations in how institutions define "online learning," and (2) students must self-identify as having a disability. According to the Americans with Disability: 2010 report, approximately 56.7 million people living in the United States reported having some kind of disability in 2010 [11]. This represents nearly 1 in 5 people in the civilian noninstitutionalized population in $2010[1,11]$. The report also reveals that the "total number of people with a disability (in 2010) increased by 2.2 million from 54.5 million in 2005" [11, p. 5]. 
Defining "disability" is important to understanding the importance of accessibility in online learning. According to the Americans with Disabilities Act of 1990, as amended, the term "disability" means, "with respect to an individual, (a) a physical or mental impairment that substantially limits one or more major life activities of such individual; (b) a record of such an impairment; or (c) being regarded as having such an impairment" [12]. According to the ADA, major life activities are broken down into two categories:

- In general

For purposes of paragraph (1), major life activities include, but are not limited to, caring for oneself, performing manual tasks, seeing, hearing, eating, sleeping, walking, standing, lifting, bending, speaking, breathing, learning, reading, concentrating, thinking, communicating, and working.

- Major bodily functions

For purposes of paragraph (1), a major life activity also includes the operation of a major bodily function, including but not limited to, functions of the immune system, normal cell growth, digestive, bowel, bladder, neurological, brain, respiratory, circulatory, endocrine, and reproductive functions. [12]

The Americans with Disability: 2010 report, which is published by the United States Census Bureau, categorizes types of disabilities into communicative, physical, and mental domains. As shared in the report, individuals can have more than one type of disability, meaning they may have disabilities in multiple domains. The three domains - communicative, physical, and mental - are presented in more detail below as they appear in the Americans with Disability: 2010 report:

People who have disability in the communicative domain reported one or more of the following:

1. Was blind or had difficulty seeing.

2. Was deaf or had difficulty hearing.

3. Had difficulty having their speech understood.

People who have disability in the mental domain reported one or more of the following:

1. Had a learning disability, an intellectual disability, developmental disability or Alzheimer's disease, senility, or dementia.

2. Had some other mental or emotional condition that seriously interfered with everyday activities.

People who have disability in the physical domain reported one or more of the following:

1. Used a wheelchair, cane, crutches, or walker.

2. Had difficulty walking a quarter of a mile, climbing a flight of stairs, lifting something as heavy as a 10-pound bag of groceries, grasping objects, or getting in or out of bed.

3. Listed arthritis or rheumatism, back or spine problem, broken bone or fracture, cancer, cerebral palsy, diabetes, epilepsy, head or spinal cord injury, heart trouble or atherosclerosis, hernia or rupture, high blood pressure, kidney problems, lung or respiratory problem, missing limbs, paralysis, stiffness or deformity of limbs, stomach/digestive problems, stroke, thyroid problem, or tumor/ cyst/growth as a condition contributing to a reported activity limitation [11, p. 1].

Each disability has a spectrum in terms of severity. The Americans with Disability: 2010 report breaks down disability data into two categories: "severe" and "nonsevere." Within the communicative domain, the spectrum for "seeing and hearing" ranges from limited to moderate impairments in vision or hearing to being blind or deaf. According to the World Health Organization, over 285 million people in the world are visually impaired: 39 million individuals are identified as blind and 246 million are identified as having moderate to severe visual impairment [13]. The results of the National Health and Nutritional Examination Surveys (NHANES) published in 2011 revealed that "nearly one in five Americans age 12 and older experience hearing loss severe enough to interfere with day-to-day communication" [14, n.p.]. The NHANES results also revealed that 48 million Americans have significant hearing loss in one or both 
ears $[14,15]$. Keep in mind these are just two examples of the wide spectrum within disabilities that fall under the communicative domain. It is also important to recognize that many disabilities can be progressive, so understanding the spectrum within a disability is important to accommodations and support services.

Within the area of accessibility, "hidden disabilities" and "invisible disabilities" are gaining greater national attention within higher education. In April 2011, the Higher Education Research Institute (HERI) at the University of California, Los Angeles, published a research brief entitled College Students with "Hidden" Disabilities: The Freshmen Survey Fall 2010. This publication drew national attention to the increasing percentage of freshmen enrolling in college who are reporting "hidden disabilities," such as attention deficit/hyperactivity disorder (ADHD) and psychological disorders as well as the importance of providing student accommodations for these students [16].

Two organizations bringing greater national attention to invisible disabilities include Disabled World [17] and the Invisible Disability Association (IDA) [18]. Disabled World defines the term invisible disabilities "as an umbrella term that captures a whole spectrum of hidden disabilities or challenges that are primarily neurological in nature" [17, n.p.]. IDA states that the term invisible disabilities:

refers to symptoms such as debilitating pain, fatigue, dizziness, weakness, cognitive dysfunctions, learning differences and mental disorders, as well as hearing and vision impairments. These are not always obvious to the onlooker, but can sometimes or always limit daily activities, range from mild challenges to severe limitations and vary from person to person [18].

Disabled World shares that 10 percent of individuals living in the United States have a medical condition that could be considered a type of invisible disability, and 96 percent of individuals self-identifying with chronic medical conditions have an illness that is invisible [17]. A full list of invisible disabilities is listed on the Disabled World web page "Information on Invisible Disabilities" [17]. Two excellent resources on invisible disabilities include a video by Disabled World entitled Invisible Disabilities \& Postsecondary Education [19] and a video by IDA entitled Invisible No More TV: Tell Your Story [20].

\section{Faculty Development and Concept of Personas}

Faculty development is essential to the design, implementation, and sustainability of online degree and certificate programs that engage all students. Zdenek states, "Students with disabilities are in danger of being either excluded from the new media revolution or accommodated as after-thoughts of pedagogies that fail to anticipate their needs" [21, n.p.]. Therefore, institutions need to consider the importance of including accessibility training as part of faculty development for all faculty (i.e., full-time, part-time, and adjunct). Accessibility training can be integrated into faculty orientations and then continue through ongoing faculty development. While professional development often includes required training on the LMS infrastructure and course facilitation, accessibility should become part of this training as well.

The integration of accessibility into online learning requires an institutional commitment to success for all students. The reality is that ADA compliance "remains a major vulnerability" for online programs, as shared in the 2010 Managing Online Education Survey, conducted by the WICHE Cooperative for Educational Telecommunications (WCET) and the Campus Computing Project [22]. According to this survey, "many institutions may be vulnerable to complaints about the accessibility issues because faculty and academic programs, rather than a central office familiar with the mandates of the Americans with Disabilities Act (ADA) are responsible for ADA compliance" [23, n.p.]. Therefore, accessibility training for online faculty requires collaboration among (a) the offices responsible for ADA compliance, (b) the offices responsible for faculty development, and (c) the offices responsible for online programs.

Accessibility training needs to go beyond providing faculty with national data on disabilities and warnings of potential litigation. Accessibility is the right thing to do and training should be focused on students, their engagement online, and program completion. It is recommended that institutions develop strategies to personalize accessibility training. One of these strategies is to apply the concept of personas. Today, personas are widely used within marketing, web design, and instructional design since the concept 
uses research to identify the patterns of thought and behavior of the end user, such as a customer, consumer, or student.

What is a persona? As defined in "Personas: The Foundation of a Great User Experience":

A persona represents a cluster of users who exhibit similar behavioral patterns in their purchasing decisions, use of technology or products, customer service preferences, lifestyle choices, and the like. Behaviors, attitudes, and motivations are common to a "type" regardless of age, gender, education, and other typical demographics. In fact, personas vastly span demographics. [24, n.p.]

The concept of personas does not typically focus on just one individual but instead describes several different types of individuals to bring the "idea" or "persona" to life. The development of personas is based on qualitative and ethnographic research methods including sociographic and psychographic data. It is through this research and collection of data that patterns emerge relating to behavior, attitudes, needs, motivation, etc. These patterns then define each persona. According to Scott Ambler \& Associates:

It is quite common to see a page or two of documentation written for each persona. The goal is to bring your users to life by developing personas with real names, personalities, motivations, and often even a photo. In other words, a good persona is highly personalized [25, n.p.].

It is recommended to update personas frequently since innovation and competition may can swiftly and significantly shift the attitudes and behaviors of the user [24].

The integration of personas into accessibility training moves the focus from statistics to having a discussion about students with different disabilities and what they need to actively engage in their courses. It is important that personas mirror real students, so include a photo of each student, his/her name, age, year of enrollment (freshman, sophomore, junior, senior), major, the student's program format (fully online, blended), etc. Describe the disability/disabilities and include a list of the technologies the student uses as well as the student's needs for his/her courses. For example, a handout or a slide can be developed with a photo of a college-age student named "Allison Tyler" with information about Allison (e.g., 19 years old, Psychology major; majority of courses are online; low vision; uses ZoomText for screen reader; etc.). Allison is then one of multiple personas representing students with disabilities from across the institution. This use of personas is an excellent strategy for personalizing accessibility training.

\section{STUDENT PERSPECTIVES: PERSONAL INTRODUCTION, CHALLENGES, AND RECOMMENDATIONS}

To introduce the concept of personas, this section provides video self-introductions and an overview of the online experience from the student perspective of one current online student and three graduates from online programs.

\section{A. Self-Introduction by Alex Cohen-http://youtu.be/Uw3PosXINNE}

My name is Alex Cohen, and I have a degenerative retinal disease known as retinitis pigmentosa (RP), which has left me with increasingly limited vision since being diagnosed over 15 years ago. RP adversely affects the rod and cone receptor cells in the retina, creating limited peripheral vision and severe night blindness. The "tunnel" of vision in those who have RP gradually shrinks until there is no useable vision left. In addition to problems with the cells of the retina itself, RP adversely affects the muscles of the iris, making the pupil unable to adapt to changes in light.

I am a graduate of the online Master of Science Program in Hospitality Management at Drexel University. My choice to enroll in an online graduate program was primarily motivated by the flexibility such a program could provide. As a nontraditional student with adult responsibilities, including raising a family, the idea of studying and completing coursework with a customized schedule that enabled greater personal control over the time and pace of my learning was appealing. The flexibility of the schedule was of higher importance than any consideration given to my visual impairment; however, the online delivery of materials through technology provided an opportunity to compensate for my limited vision. 
As an online graduate student, the three greatest challenges that I incurred were (1) PowerPoint presentations in which screen readers could not recognize text content; (2) video or streaming content in which the critical learning objectives might be lost for students without sight; and (3) navigating through third-party websites and reference software that conflicted with screen reading software programs. There are many screen-reading software options available with varying strengths and weaknesses that attempt to fulfill the individual learner's needs based upon his or her level of sight and the course material involved.

Why are these three challenges problematic from a student's perspective? PowerPoint slideshows in which audio is recorded continuously "over the slides" create video presentations that allow learners to pause, rewind, and forward the video at their pace. However, such a tool can be problematic when the written content or embedded text on the slides provides critical information that a screen reader will not recognize.

Videos and streaming content are often used within online course content. However, the type of video used is very important when considering accessibility. For example, most video content can be learned through auditory means if the videos are of interviews or documentaries. Accessibility becomes a challenge when the video relies heavily on text information that is presented simultaneously and requires the student to read what is being shown or demonstrated.

Requiring students to download documents (PDF or otherwise) from different Internet sites, search through databases, and use reference search tools may not always provide an efficient accessible environment for assignments that have short turnaround times. Although internal support services greatly help facilitate this process, due dates and turnaround times for assignments should be a consideration when developing a course.

What I enjoyed most about being in an online program was the comradery with my fellow students and a sense of co-learning that I felt with them. I felt highly engaged in class discussions and group projects with colleagues scattered throughout the country. Support services, such as the Office of Disability Resources, ensured that I would share the same scholastic experience as my peers, and I felt increased confidence in having that additional support for the technical challenges. In some ways, I became closer to both the professors and my classmates because the online environment required active participation.

Also, learning contracts gave me greater flexibility in determining my own goals for the course, learning resources and strategies, evidence of accomplishments, along with the criteria and means for validating that evidence. A learning contract can be defined as an agreement form that students develop with the Office of Disability Services and their professors to identify goals and accommodations specifically for a course. The negotiated learning contract with my professors empowered me to have an active role in the learning process. I also felt a greater level of self-determination, which was a self-reflective process that centered on identifying my unique strengths and weaknesses and my life and professional experiences that connect to my learning needs.

I have four primary recommendations for higher education institutions offering online programs:

1. Ensure consistent procedures are in place throughout all departments and programs so professors and students have one stable resource for guidelines and information.

2. Continue to monitor the needs of learners, as many disabilities are progressive or may change over the course of an academic year or years.

3. Create course content, institutional resources, and orientation materials that are accessible.

4. Provide opportunities for the learner to participate in setting personal learning objectives and modes of delivery that best suit their needs.

Having uniform procedures for students and professors to follow for designing courses, making materials accessible, and obtaining support services provides a faster and more seamless process for learning and participating. Unfortunately, not all course material will be immediately accessible. Improvisation occurs from time to time; however, as soon as the syllabus or course material changes, accessibility of the new content must be considered. 
Some disabilities are constant while others may be exacerbated by a variety of stimuli, and others are progressive (a student's vision may change, and as a result the software used may become ineffective). And screen readers possess better functionality in certain areas than others. For example, some screen readers are much better for reading mathematical equations and graphs and charts, while others are better for reading PDF documents. Keeping informed about new technological advances and ensuring the most up-to-date needs of the student are being met will create a better service dynamic between the institution and student.

Certain course materials (e.g., orientation, lectures, etc.) within online programs are provided via streaming video. The video consists of a live or archived broadcast of a presenter speaking over the training materials. These videos may not work well with screen readers since the content being shown during the presentation cannot be read by a screen reader, and magnification may not always be effective either, which leaves the learner frustrated and in some instances leads to miscommunication or misunderstanding of critical course content.

The online educational environment requires self-direction. Overcoming accessibility issues may enable a learner who has experienced dependency on others because of, for example, decreased vision, an opportunity for a greater sense of independence through technology. Additionally, an understanding of one's own level of readiness to engage in online methods of delivery can lead to increased confidence that a successful outcome will be the result of one's efforts even if technical or technology challenges arise.

\section{B. Self-Introduction by Henry Alphin- http://sloanconsortium.org/sites/default/files/HenryAlphin-JALN2013.mp4}

My name is Henry C. Alphin Jr. I have a speech impediment-stuttering, to be specific. When most people consider disabilities, stuttering is not the first type of impairment that comes to mind. However, stuttering can be debilitating, particularly to a student's mental well-being. College is a difficult place for stutterers to acclimate, and if they do attend college, it can be a frustrating experience.

I am a graduate of the online Master of Science in Higher Education (MSHE) program at Drexel University. I chose to enroll in an online program because of the flexibility in program structure and the importance of the program - including the types of courses, quality of the faculty, and strength of reputation - to my career aspirations. Regarding the flexibility of the program, the online MSHE program allows students to continue their professional careers while taking courses and working on projects, including the culminating thesis. This flexibility was important because I was accustomed to being a parttime student, even as an undergraduate economics major in Drexel's Bennett S. LeBow College of Business.

There are very few services available to online students who stutter, and the reality is that there's not much that can be done to help. However, the fact that online students do not have to spend each day in front of a class giving presentations where understanding the topic is only $10 \%$ of the struggle, but communicating that understanding is more difficult, is an enormous benefit.

On a broad scale, the challenge has been a lack of available resources for students with disabilities in online learning. Therefore, an educational framework, such as universal design for learning (UDL), is critical to online learning. UDL is a framework for designing educational environments that are conducive to all learners participating and gaining knowledge [26]. Unless there is a UDL process that promotes accessibility as a culture, then individual students have to self-identify and report their issues in order to receive assistance. This lack of accessibility is generally the case with brick-and-mortar programs as well, but the very existence of e-learning provides an opportunity for many disabled students to obtain a university education. Drexel University has been a leader in this area, and my research on e-learning accessibility has helped to improve accessibility in the MSHE program.

What I enjoyed most about being in an online program was the ability to use technology to network and complete projects. I've been able to network extensively and build lasting friendships, just as I have in traditional programs. Technology makes communication a much smoother process for me, both as a 
disabled student creating content and as one who is storing content for later utilization.

The greatest challenge for me as an online student had to do with student-generated content. For students with speech impairments, the accessibility issue is less about comprehending the content received and more about how the student generates content. For instance, reducing focus on the timing element in recorded discussion boards allows the student to pause or simply get through the speaking requirement. When students with speech impairments participate in synchronous learning environments, Burgstahler [27] recommends providing extra time for the student to speak, or to simply ask the student to repeat what has been said, if something has been misunderstood. Voice discussion boards and voiceover PowerPoint presentations can be difficult and daunting for a student with a speech impairment. Audio assignments that may take an online student 3-15 minutes to record can easily take me one to several hours to record due to re-recordings. Group audio presentations also provide challenges, particularly if there are is little lead time to complete the assignment.

The primary recommendation that I have for institutions that offer online learning is that e-learning accessibility must become a part of the "culture" of the program and institution. It is important for institutions of higher education (IHEs) to have leaders who:

are knowledgeable about how to create a culture of accessibility [26], which includes: effective hiring practices, as well as a system of accountability through outcomes assessment [26];

are willing to institute accessibility as a foundational element of the institution's culture [26];

are willing to consider and implement project management theory in developing and improving an elearning program [28]; and

possess the power and support to make effective and needed changes.

In addition, collaboration with departments beyond the program or school, including the institution's office of disability services and office of institutional research, can make the process more easily achievable, improve the chances of the longevity of the accessibility culture, and decrease the overall burden on the disabled student [26].

A final topic to consider is self-identification. A culture of inclusion focuses on abilities, making students feel more comfortable about self-identifying and disclosing disabilities because they feel that everyone involved wants them to succeed. An e-learning environment is the perfect realm for inclusivity, and IHEs can all work harder to make sure that their environments are inclusive, collaborative, and accountable.

\section{Self-Introduction by Daniel Veit—http://youtu.be/FdwhQjpAzmY}

My name is Daniel Veit, and I identify myself as a deaf individual who uses American Sign Language to communicate with others. Due to the fact that sign language was the very first mode of communication and language I used, I consider American Sign Language my first language and English my second language. There are many variations in the causes and degrees of hearing loss and communication methods, so I would like to emphasize that I represent a small part of the deaf and hard of hearing population.

I have had many different experiences with my education throughout my life, starting with attending a state school for the deaf at an early age, then transferring to an elementary school in a local school district that had a mainstreaming program. I had to use interpreters for most of my classes. Upon high school graduation, I went to Gallaudet University in Washington, DC, which is known as the only liberal arts university for the deaf and hard-of-hearing students in the world. My experience at Gallaudet University marked the first time I had full access to education and direct communication in terms of having the opportunity to build relationships with professors and the ability to participate in classroom discussions.

I am currently an online graduate student pursuing my Master of Science degree in Higher Education at Drexel University. I chose to enroll in an online program because of the schedule flexibility and the ability to complete the program anywhere, meaning distance from the physical campus is not a factor.

Though online learning has definite advantages, three of the greatest challenges for an online student who 
has a hearing impairment or who is deaf include (1) videos and voiceover PowerPoint presentations that are inaccessible because they do not have any captions, (2) voice discussion boards, and (3) group projects using PowerPoint presentations. Logging into an online course and realizing that you have limited access to the course content can be terrifying and frustrating. It is important that students let faculty know immediately what is accessible and what is not. Students must also work closely with the office of disability services upon matriculation to discuss services. For me, working with the Office of Disability Resources at Drexel was critical to making sure that I received appropriate accommodations for the audio-based content and assignments and to making my online experience a more positive one. In fact, as an online student, I am now able to enjoy something that I could not during my $\mathrm{K}-12$ education, which is direct communication with my professors and classmates. Personally, I feel as if my classmates know me as Daniel, rather than as a "deaf student with an interpreter," which is nice experience and change.

I have four recommendations for higher education institutions that offer online courses and programs to ensure full accessibility with their online content and materials: (1) understand the importance of audiobased content since research indicates that one in five Americans has significant hearing loss; (2) have captions embedded in the content of PowerPoint presentations rather than having a separate printed text transcript; (3) discuss the importance of interpreters for group projects in which students are required to present audio content; and (4) make sure students are aware of the services offered by the office of disability services so students can establish a relationship early on.

The first thing that administrators, instructional designers, and disability support specialists should do is look at audio-based content and assignments and make sure they are captioned. Online learning is evolving quickly, and from what I have seen, there are more links to video clips, and voice recordings are being used often now compared to the past, when online courses were largely made up of articles, reading, and writing.

For the deaf and hard-of-hearing students, it is essential to be able to view and access video clips, PowerPoint slideshows, and lecture recordings. It is strongly recommended to have captions embedded in the content rather than having a separate printed text transcript, especially for content that has lectures that incorporate visual aids, as it is very helpful to be able to receive information from the verbal and the visual aid simultaneously. Reading a transcript and viewing a video that includes visual aids at the same time can be time-consuming, as one has to pause the video, read a transcript in hand, and then go back to the video and play it. However, if embedding captions is not possible, the second-best option is a textprinted transcript of the audio recording.

As for assignments that require audio recordings, I have tried different strategies, including sending a recorded video clip of my messages in American Sign Language to disability services, where they would have it translated by an interpreter. The results were not always positive and accurate, as the interpreters were not familiar with the jargon words I wanted to use for my voice discussion board posts. I have had more positive experiences by having a "live" interpreter, whether it was in person or through a video remote interpreter (VRI), as I am able to clarify if the interpreter(s) didn't understand a specific word or concept.

Lastly, I cannot emphasize enough the importance of establishing a relationship with your disability support specialist and being open with your instructors about your disability and needs so that you can succeed with your online learning. It is also important for students with disabilities to see themselves as "pioneers" in this field and provide assistance and directions to disability services on which kind of accommodations worked and which didn't, as online learning is still a relatively new field with rapidly evolving technologies.

\section{Self-Introduction by Chanel Broadus_http://youtu.be/dHZI_CLV-4}

My name is Chanel Broadus, and I have carpal tunnel syndrome (CTS). CTS is the result of added pressure from the swelling of a membrane around the tendon on the median nerve of the hand. The added pressure results in discomfort in the form of numbness, tingling sensations, and pain [26]. CTS is 
treatable, but in more severe cases it can lead to permanent nerve damage. It is common among people who perform repetitious vigorous activity with their hands, such as typing; however, very few people realize it is a qualifying disability. The Arthritis Foundation provides extensive information about CTS including what it is, what causes it, what its effects are, how it is diagnosed, its treatment options, and its risk factors [29].

I am a graduate of the online Master of Science in Higher Education Program at Drexel University. My decision to enroll in the program was based on my need to have flexibility as a mother and enthusiastic higher education professional. While it was important for me to achieve my academic goals, it was equally important for me to have the ability to focus on my children, who were very young when I entered the program. I also wanted to have some level of control over how fast I could obtain my degree. By going to school online, I could advance at the pace I felt was necessary, and complete courses year round with short breaks in between. A final motivation for going to school online was the delivery method. I enjoy technology and found my classes more engaging than sitting in a traditional classroom because I was presented with many opportunities to incorporate the many facets of our technological age into my learning.

As an online graduate student, my three greatest challenges were being able to participate in (1) text discussion boards; (2) group assignments; and (3) writing papers. When I first enrolled in the program, I was not aware that my condition was even considered a disability. I struggled through the pain in my hands during my first quarter in an effort to complete the requirements successfully. While I was triumphant, the repetitious typing took a toll on my hands, and a fear of having to withdraw ensued. My advisor recommended I contact ODS, and I quickly learned after submitting the proper documentation that I had a qualifying disability. Although CTS is common, I hadn't thought of it as a disability, and I would have never thought that I could receive accommodations that would help me be successful in my academic studies. Moreover, the ODS provided information about how to overcome the hurdle of typing.

Advancements in technology have created options for accessibility that I did not previously know existed. For example, ODS introduced me to many voice-activated software options that I could use to transcribe my information so I did not need to type. I learned that Windows includes a speech-recognition component that allows users to speak into a microphone and dictate information for written documents. There were many other speech-recognition software options available, such as Dragon Naturally Speaking, which is an effective choice. Using these options took some getting used to, but once I mastered them, they were priceless.

In addition to using voice recognition software, I was also able to post information to discussion boards as MP3 files using an iPod (which all students received upon enrollment). Creating and uploading the files was easy, but getting my peers to acknowledge them was a challenge. My posts were not the norm, and depending on the browser a student or professor used, access was sometimes difficult. As a result, I often felt that my input was overlooked. I struggled with participating in the engaging conversations that many of peers participated in, but over time they caught on and became more open to listening to my feedback.

Because of my success with recording audio clips and using voice-recognition software to write papers, I used both methods for group projects. In the beginning, others thought of having me as a partner as a challenge. I was the student who did not type her responses and did everything in a rather abnormal manner. However, my peers gradually started to view me as an asset because I frequently used innovative technology. For group work, the best thing to do was divide the work based on strengths. My clear weakness was typing, but I could make up for my impediment through speech and unique delivery.

What I enjoyed about being in an online program was the opportunity to use technology. Taking classes online provides a wealth of opportunity for exploration and creativity that does not exist in the traditional brick-and-mortar environment. It also gave me the flexibility I needed as a mother to care for my young children while pursuing my own academic goals. School never felt like it was in the way because I could make it fit into my schedule. I could learn $24 / 7$ because my program was, figuratively speaking, always open. The number one benefit of being a part of my program was that my children got to see firsthand 
what it took to be successful in higher education. People often talk about what it takes, but my children got to see it up close and personal, which instilled in them an appreciation for education.

There are four primary recommendations that I have for higher education institutions that offer online courses and programs:

1. Create platforms that promote various delivery methods for discussion, such as written text, video, and voice.

2. Educate instructors about CTS and the various accommodations it requires, so they can access alternative methods of response and design assignments that are alternative-response friendly.

3. Provide solid voice-recognition software that is easy to use.

4. Educate students about ergonomics and cost-effective solutions for implementation at home.

These four recommendations will assist students who suffer from CTS and serve as preventive measures that will minimize the likelihood that more students will develop CTS.

Online programs need to create platforms that promote various delivery methods for discussion, such as written text, video, and voice. These options should be available to all students to support online engagement and should not make students such as myself stand out, but encourage them instead to embrace the positives of using technology.

Instructors should also receive education about working with online students who have CTS, as it is a common condition among avid computer users. Providing information to educators will help them better understand the needs of their students so they can create assignments that will work well with all response formats. Moreover, educators need to understand what the various response formats are, how to download them, and how to access them. I had one professor who struggled to access my content. As a result, my feedback was always delayed, which made it difficult to gauge my comprehension of the course material and my progress.

Access to voice-recognition software for online students to use at home is very important. For students who are on campus, computer labs may provide free access to speech-recognition software. However, online students who are unable to come to campus must purchase the software on their own. Institutions must work on closing the gaps between on-campus or local students and online students to promote academic success for all students.

Finally, educating online students about the importance of ergonomically correct sitting posture is an absolute necessity. As more people turn to online education as a way to achieve their academic goals, more people will develop CTS. However, showing students the proper way to sit and type, and providing them with cost-effective options for purchasing ergonomic computer accessories will help reduce the number of cases of CTS that surface as a result of the repetitious typing that the online environment demands.

Very few people realize CTS is a disability, but it is a very common condition. I learned this fact by luck and took it upon myself to research all my options, which prevented me from dropping out of my master's degree program. It is important for students to know that if they are having difficulty completing their studies, they should talk to someone. Students can be successful online if they have CTS, but they need the support of their institutions to help them achieve.

\section{CONCLUSION}

Online learning requires an institutional commitment to accessibility. Accessibility should not be an afterthought or be addressed on a course-by-course basis after a student has self-identified as having a disability. Accessibility should also not be compartmentalized to the office of disability services. According to Betts, "Accessibility must become part of the institutional culture with a commitment across all divisions, offices, services, and programs" [30, n.p.].

It is recommended that accessibility training for faculty include ADA definitions, ADA regulations, national data, and institutional data. However, it is also recommended that institutions integrate the 
concept of personas to provide a personalized approach to working with students with disabilities and to assist faculty with aligning their dynamic instructional and assessment strategies with today's diverse student population.

Increasing awareness about the importance of accessibility in online learning begins with each of us. If you have found this article to be beneficial to understanding the importance of accessibility to online learning and student success, the authors encourage you to share this publication link across your campus and with colleagues. An additional resource on understanding disabilities from a student's perspective is from the Sloan-C Accessibility Webinar Series 2013 - Student \& Alumni Panel: What Students with Disabilities Want \& $\quad$ Faculty Administrators to Know: http://sloanconsortium.org/institute/webinars/2013/accessibility-series [31]. You may also consider becoming part of Sloan's Sloan-C Special Interest Group for Integrating Accessibility into Online Higher Education: http://commons.sloanconsortium.org/groups/integrating-accessibility-online-higher-education [33].

\section{REFERENCES}

1. United States Census Bureau. Nearly 1 In 5 People Have A Disability In The U.S., Census Bureau Reports (July 25, 2012). http://www.census.gov/newsroom/releases/archives/miscellaneous/cb12134.html

2. United States Government Accountability Office. Higher Education \& Disability: Education Needs A Coordinated Approach To Improve Its Assistance To Schools In Supporting Students. Report to the Chairman, Committee on Education and Labor, House of Representatives. (October 2009). http://www.gao.gov/new.items/d1033.pdf

3. Allen, I.E. and Seaman, J. Changing Course: Ten Years of Tracking Online Education in the United States (January 2013). http://sloanconsortium.org/publications/survey/changing course 2012

4. Nagel, D. Online Learning Set for Explosive Growth as Traditional Classrooms Decline. (November 26, 2011). http://campustechnology.com/articles/2011/01/26/online-learning-set-for-explosivegrowth-as-traditional-classrooms-decline.aspx

5. Diaz, D.P. Online Drop Rates Revisited. The Technology Source (2002). http://technologysource.org/article/online_drop_rates_revisited

6. Frankola, K. Why Online Learners Drop Out. Workforce, 80, 53-58 (2001).

7. Dagger, D. and Wade, V.P. Evaluation of Adaptive Course Construction Toolkit (ACCT) (2004). http://www.dcs.warwick.ac.uk/ acristea/AAAEH05/papers/6-a3eh_daggerd_IOS_format_v1.1.pdf

8. Flood, J. Read All About It: Online Learning Facing 80\% Attrition Rates. Turkish Online Journal of Distance Education 3(2) (2002). http://tojde.anadolu.edu.tr/tojde6/articles/jim2.htm

9. Angelino, L.M., Williams, F.K., and Natvig, D. Strategies to Engage Online Students and Reduce Attrition Rates. The Journal of Educators Online 4(2): 1-14 (2007). www.thejeo.com/Volume4Number2/Angelino\%20Final.pdf

10. Eduventures. Online Higher Education: Retention, Benchmarks and Practices, Part 1: What do we know? (April 2007). http://www.eduventures.com/services/supplier-services/reports

11. Brault, M. Americans With Disabilities: 2010, Current Population Reports. U.S. Census Bureau (July 2012). http://www.census.gov/prod/2012pubs/p70-131.pdf

12. Americans with Disabilities Act of 1990, as Amended. Title 42-The Public Health and Welfare, Chapter 126-Equal Opportunity for Individual with Disabilities, Sec. 12102. Definition of Disability (2009). http://www.ada.gov/pubs/adastatute08.htm

13. World Health Organization. World Report on Disability. World Bank: Malta. (2011). http://www.who.int/disabilities/world_report/2011/en/index.html

14. Conely, M. One in Five Americans Age 12 and Older Experience Hearing Loss Severe Enough to Hinder Communication. ABC News (November 15, 2011). http://abcnews.go.com/Health/americans-hearing-loss/story?id=14949805\#.ULFFdY76ZQs 
15. Lin, F.R, Niparko, J.K., and Ferrucci, L. Hearing Loss Prevalence in the United States. Archives of Internal Medicine 171(20): http://archinte.jamanetwork.com/article.aspx?articleid=1106004

16. Higher Education Research Institute (HERI). College Students with "Hidden" Disabilities: The Freshmen Survey Fall 2010. The Cooperative Institutional Research Program (CIRP). (January 2011). http://www.heri.ucla.edu/PDFs/pubs/briefs/HERI ResearchBrief Norms2010.pdf

17. Disabled World. Invisible Disabilities. What are Invisible Disabilities? http://www.disabledworld.com/disability/types/invisible/

18. Invisible Disabilities Association. Home Page. http://www.invisibledisabilities.org/ (May 29, 2009).

19. Disabled World. Invisible Disabilities and Postsecondary Education. Video (May 29, 2009). http://videos.disabled-world.com/video/163/invisible-disabilities-postsecondary-education

20. Invisible Disabilities Association. Invisible No More TV: Tell Your Story. Video (Oct. 13, 2011). http://www.youtube.com/watch?feature=player_embedded\&v=ufKAyeum8dU (May 29, 2013).

21. Zdenek, S. College Students on the Margins in the New Media Classroom. Accessible Rhetoric (May 26, 2008). http://seanzdenek.com/article-accessible-podcasting/

22. Parry, M. ADA Compliance Is a "Major Vulnerability" for Online Programs. http://chronicle.com/blogs/wiredcampus/ada-compliance-a-major-vulnerability-for-onlineprograms $/ 28136$

23. WICHE Cooperative for Educational Telecommunications (WCET) \& The Campus Computing Project. Managing Online Education Survey (2010). http://www.campuscomputing.net/item/2010-managing-online-education-survey-wvideo

24. O'Connor, K. Personas: The Foundation of a Great User Experience. http://uxmag.com/articles/personas-the-foundation-of-a-great-user-experience (May 25, 2013)

25. Scott W. Ambler \& Associates. Personas. http://www.agilemodeling.com/artifacts/personas.htm (May 25, 2013).

26. Alphin, H.C. E-Learning Accessibility Model: A Culture of Collaboration and Outcomes Assessment. International Journal of Online Pedagogy and Course Development (IJOPCD)-Special Issue on Advanced Technology in Education (2013 - in press).

27. Burgstahler, S. Universal Design of Technology Environments: From Principles to Practice. In S. Burgstahler \& R. C. Cory (Eds.), Universal Design in Higher Education: From Principles to Practice. Cambridge, MA: Harvard Education Press, 213-224, 2010.

28. Alphin, H.C. Accessibility Implementation for Disabled Students in PMBOLD Environments. In G. Eby \& T.V. Yuzer (Eds.), Project Management Approaches for Online Learning Design. Hershey, PA: IGI Global (2013 - in press).

29. Arthritis Foundation. Disease Center. http://www.arthritis.org/disease-center.php?disease id=8

30. Betts, K. S. Creating an Institutional Culture That Embraces Accessibility and Supports Online Student Success. EvoLLLution http://www.evolllution.com/opinions/creating-an-institutional-culture-that-embraces-accessibilitysupports-online-student-success/

31. Sloan-C Accessibility Webinar http://sloanconsortium.org/institute/webinars/2013/accessibility-series

32. Sloan-C Special Interest Group for Integrating Accessibility into Online Higher Education. http://commons.sloanconsortium.org/groups/integrating-accessibility-online-higher-education

\section{ABOUT THE AUTHORS}

Kristen Betts, EdD, is the Chief Academic Officer at Forbes Education. Dr. Betts has served as the Director of Online and Blended Learning at Armstrong Atlantic State University and the Senior Director for eLearning at Drexel University. Additionally, Dr. Betts has served as the Director of the blended EdD Program in Educational Leadership and Management program for the Philadelphia campus and the founding Director of the online Master of Science in Higher Education program at Drexel University. While at Armstrong and Drexel University, she led program and campus initiatives that received 
distinguished statewide, national, and international awards. Dr. Betts has been a keynote speaker at conferences and government-supported events in Sweden, South Korea, Canada, and across the United States. She serves on several advisory boards and as a conference reviewer for several national and international associations. Dr. Betts is a Quality Matters certified peer reviewer and master reviewer. She is also a Higher Education Resource Services (HERS) Institute alumna and has been a reviewer for the Journal of Asynchronous Learning Networks (JALN), Journal for Online Learning and Teaching (JOLT), Journal of Online Pedagogy and Course Design (IJOPCD), Journal of Tourism \& Hospitality (JTH), and EDUCAUSE Quarterly (EQ). Dr. Betts publishes and presents nationally and internationally on online and blended education, student/faculty recruitment and retention, adult learning, branding, Online Human Touch, Online First-Year Experience, eAdvising, eStudent Affairs, dashboards, accessibility, cooperative education/work integrated learning, stackable credential programs, and faculty development.

Alex H. Cohen is currently a $\mathrm{PhD}$ student in marketing at the LeBow College of Business at Drexel University, where his research focuses on accessibility marketing. Prior to beginning his doctoral program, Alex taught courses as an adjunct professor in Drexel University's School of Hospitality Management. He has over 15 years of experience in the hospitality industry, holding positions such as director of sales and marketing, general manager, and senior VP of operations. As a nontraditional student, Alex completed his master's degree in hospitality management in an online program at Drexel University. Diagnosed at age 20, Alex has a degenerative retinal disease known as retinitis pigmentosa, which has robbed him of most of his vision. Alex lives in downtown Philadelphia with his wife and two young sons.

Daniel P. Veit is currently an Assistant Supervisor for Career and Transition Department at Texas School for the Deaf in Austin and oversees three different programs; Adult Curriculum for Community, Employment and Social Skills (ACCESS), Career and Transition Services (CTS) and Career Technical Education (CTE). Prior to working at Texas School for the Deaf, Daniel worked as a Career Consultant for six years at Gallaudet University in Washington, D.C. Daniel completed his Master of Science Degree in Higher Education, and wrote a thesis related to deaf and hard-of-hearing students taking online classes, focusing on their accessibility issues and experiences.

Henry C. Alphin Jr., MS, is a higher education administrator and research affiliate at Drexel University, and a higher education consultant. His higher education areas of specialty include economic impact, development, and analysis in higher education; philosophy of higher education; the history and future of global accreditation; e-learning accessibility and disability theory; virtual worlds and higher education; Humanity 2.0 and higher education; innovation and creativity; change management; and strategic management. Mr. Alphin holds a Bachelor of Science in Economics from Drexel's Bennett S. LeBow College of Business, a Master of Science in Higher Education (MSHE) from Drexel's School of Education, and he is a Master of Business Administration (MBA) student at the Warwick Business School of Warwick University. His MBA dissertation, under Steve Fuller, is on the economic impact of Humanity 2.0 on higher education.

Chanel Broadus is currently an adjunct professor at Camden County College for the Reading and Writing Skills Department. She is also an alumnus of the Master of Science in Higher Education Administration program at Drexel University. She possesses a Bachelor of Science degree in Legal Studies from Saint Joseph's University and an Associate in Applied Science in Paralegal Studies from the Community College of Philadelphia. Ms. Broadus has over ten years of professional experience of administration in higher education, the legal profession, and information technology. Prior to her position at Camden County College, Ms. Broadus worked at the Community College of Philadelphia as an administrator in the Office of Academic Advising where she was directly responsible for the redesign of the departmental operations to ensure its daily success.

Dan Allen is currently an Accessibility Specialist in Drexel University's Goodwin College and School of Education. He serves as co-chair of Drexel's Online Accessibility Committee. Dan has been working in higher education for over 30 years, with careers in academic advising, web design, and instructional design. He has been a long time advocate of web accessibility and usability. 